\title{
SURVEY AND RESTORATION: NEW WAYS OF INTERACTION
}

\author{
C. Battini ${ }^{\text {a }}$, R. Vecchiattini ${ }^{\text {b, * }}$ \\ ${ }^{\text {a }}$ DICCA, Department of Civil, Chemical and Environmental Engineering, Via Montallegro 1, University of Genoa, Italy - \\ carlo.battini@unige.it \\ ${ }^{\mathrm{b}} \mathrm{DAD}$, Architecture and Design Department, Stradone Sant'Agostino 37, University of Genoa, Italy - \\ rvecchiattini@arch.unige.it
}

KEY WORDS: structural model, monitoring, three-dimensional survey, retopology, parametric representation

\begin{abstract}
:
The present paper analyses two cases exemplifying a possible use of survey and its elaborations in the field of conservation: the bell tower of the Basilica Santa Maria delle Vigne and the Chiesa di San Matteo, both situated in Genoa. In the first case, the threedimensional survey was used as a basis to build a model for the structural analysis. The need for an accurate database created with the three-dimensional survey allowed the research team to determine and highlight the critical points of the structure as the thickness of vaults and floors, the location of loads and the inclination of the walls. The data collected was used to create an accurate 3D model to be tested with simulations, in order to verify the stability of the bell tower when applying stress and limitations. In the second case, the three-dimensional survey was used as the basis for the collection, management and representation of the data derived from the survey on rising damp. The purpose was to test a dynamic data processing system that could be used as a tool to collect data on site as well as to access data remotely. By using software for three-dimensional representation and a node programming language, it was possible to define a system that offered dynamic viewing and was easy to use, through the use of chromatic scales and level curves, which can be generated starting from tables containing numerical data. Surveying, diagnostics, modelling and representation allow one to experiment with new ways of interaction within the common goal of conservation.
\end{abstract}

\section{INTRODUCTION}

The use of advanced technology can help experts and researchers in the field of Cultural Heritage, in finding techniques and applications able to translate the requirements which are constantly changing - of registration, knowledge, forecasting, quantification and storage or exploitation of the artefact. However, hyper-specialisation, which is an increasingly required professional trait, risks alienating those who study the complexity of real objects, by fragmenting them into their smaller components. Hyper-specialisation makes it difficult to manage this complexity, even when one succeeds in understanding it, because different fields of knowledge often use incompatible conceptual tools. It is possible to use or implement efficient tools only if researchers share their goals, as it is shown in the two case studies of the present paper.

Three-dimensional surveys, diagnostic investigations, predictive models, visualisation, interpretation, and the representation of the data collected are only some of the basic elements needed to understand both an artefact and the designing solutions compatible with its conservation.

In the field of three-dimensional surveying, there are numerous methods to acquire data with known definition levels and errors, depending on the equipment used. The current digital survey techniques are characterised by a serious difficulty in managing and returning data, although they enable the acquisition of fundamental information for the analysis and the study of the artefact, generating digital copies, in which measurement errors are extremely reduced. This could be crucial in the use of predictive models designed to describe and discretise reality, which is far too complex. Thanks to these models, the world can be simplified, becoming a place where it is easier to operate and progress with the use of reason. However, it is important to be sure of the configuration to be able to evaluate the responses as well as to focus on the problems to be addressed and, above all, one must adapt to reality without attempting to force it or distort it into the limits of a prefigured model. For this reason, the accuracy level of a model varies depending the goals, the level of knowledge that can be achieved and the tools that can be used. The bell tower of the Basilica S. Maria delle Vigne needed a particularly accurate model to be used with predictive aims to experiment how the structure vibrated in relation to the bell sound and to provide precise indications of exercise.

Diagnostic investigations, which are useful to investigate the degradation phenomena threatening an artefact, are widely used before choosing the kind of interventions to implement. However, it is often difficult to have access to software allowing one to store and cross-check the large amount of data that inevitably accumulates when several diagnostic campaigns are carried out along with the configuration of monitoring operations. In the case of the Abbazia di S. Matteo, a dynamic data processing system was tested to be used as a tool to collect data on site and to access data remotely. Thanks to the use of software for three-dimensional representation and a node programming language, it was possible to define a system that offered dynamic viewing and was also easy to use trough chromatic scales and level curves, which can be generated starting from tables containing numerical data.

\section{THE BELL TOWER OF THE BASILICA SANTA MARIA DELLE VIGNE IN GENOA}

The bell tower of the Basilica delle Vigne, located in the heart of Genoa's old town (Figure 1), dates to the twelfth century. It 
is the oldest existing tower bell in the city together with that of the church of S. Giovanni di Pré (built almost immediately afterwards in 1180). The bell tower is a large stone structure with a square base, around 54 metres high, built on large lancet arch and ending with an octagonal stone spire that has four pyramidal pinnacles on its corners. The presence of sixteenthcentury brick barrel vaults, simple and double timber-suspended floors, girder floors, and concrete and masonry flooring systems (restored in 1958 by A. Dillon) shows a complex puzzle of interventions across the centuries. The vertical connections mostly stairs on flying brick vaults or buttresses - are also the result of several modifications, which were carried out during the seventeenth and eighteenth centuries, making a thorough understanding of the tower's structure even more difficult.

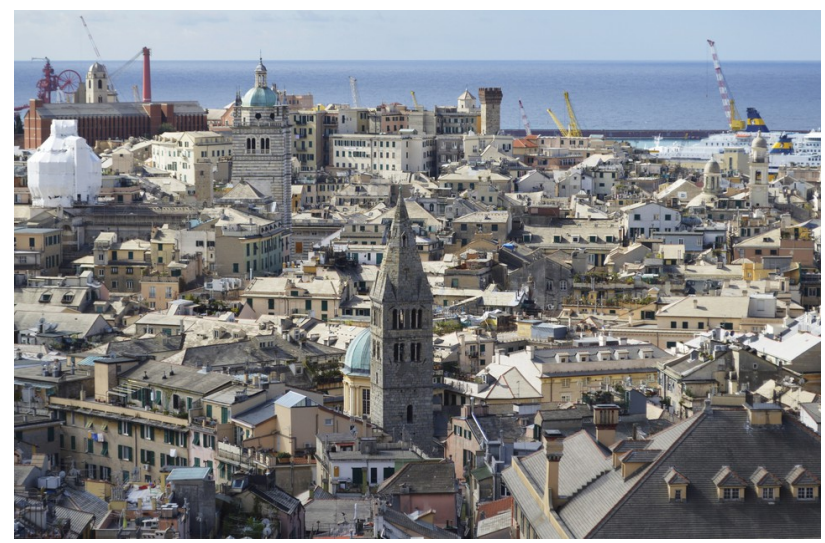

Figure 1. The Romanic bell tower, in the centre, within the dense Medieval town centre (A. Schiappapietra)

\subsection{The consolidation and restoration project}

In its first phase, the project ${ }^{1}$ - for which funding is currently being raised - aims to consolidate and restore the structure of the building, to enable full accessibility to the bell tower (Vecchiattini et al., 2016). The experience of walking up a Romanic tower, which is closed in with stone walls for the first 30 metres and then unexpectedly opens up with its double- and triple-mullioned windows onto the roofs of the city, is undoubtedly fascinating. This is the reason why the client wishes to obtain - with the necessary safety restrictions - the fruition of the tower.

The internal structures, especially horizontal features and stairs, are currently in conditions of severe deterioration due to heavy water seepage leaking in from the mullioned windows of the bell chamber. The open structure of the bell chamber is on the one hand an interesting feature, but on the other hand it is the cause of its degradation and instability. In fact, besides seepage, which causes mortar to break, bricks to crush and marlstone calcar to chip away, the bell chamber also shows a series of cracks on the corners signalling that they are being stressed by excessive compression. This is because the chamber, half of which is constituted by windows, holds the weight of the heavy

\footnotetext{
The project was developed thanks to agreement with the Parish of S. Maria delle Vigne (Mons. N. Anselmi) and the Design and Architecture Deparment (scientific coordinator, arch. R. Vecchiattini) with the support of a dissertation team of the School of Specialisation in Cultural and Landscape Heritage, Genoa (Ing. M. D'Andrea and Arch. E. Serpe) as well as another dissertation team of Construction Engineering-Architecture, Genoa (B. Di Napoli).
}

squared-stone spire, around 16 metres high, as well as the frame structure of 5 large bronze concert bells ${ }^{2}$.

The cracks in the chamber and the condition of the horizontal elements and stairs led to a detailed study of these constructive elements as well as the development of an interpretative model to allow for structural evaluation. It was not possible to implement load tests nor mechanical-characterisation tests on the various studied structures (walls, vaults and stairs), because they could have been too dangerous and invasive for the bell tower. Therefore, it was necessary to obtain an extremely detailed knowledge of the structures to produce the most reliable interpretative model possible to be used in the following qualitative and quantitative evaluations of the structural conditions.

\subsection{Surveying as an aid to interpration}

The archaeological analysis mainly focused on the volumes of the architectural complex to understand the stratigraphic relationship of the bell tower with church and cloister as well as between the various horizontal and vertical elements inside the bell tower and the relationship between these elements with the walls of the tower. This analysis showed an evident connection between the bell tower and the church, which was built previously $^{3}$. The stone walls of the tower lean - until the fourth level - onto the stone wall of the church, using it as a fourth wall, while, from the fifth level upwards, the bell tower has its own four walls, tightly gripped to its corners. The stratigraphic relationship between the bell tower and the cloister is also evident. On the ground floor the wall cuts through the cross vaults of the cloister, which means they were built before the wall. On the other hand, on the first floor, the cross vaults of the cloister are built leaning onto the wall of the bell tower, which means that the second floor was built after the bell tower. ${ }^{4}$ This interpretation draws upon exhaustive documentary material and it allows a schematic reconstruction of the main constructive stages of this architectural complex (Figure 2).
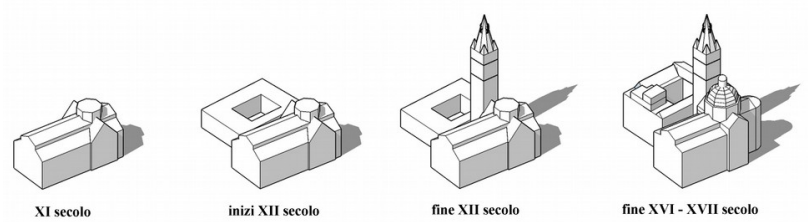

Figure 2. Schematic reconstruction of the constructive phases of the architectural complex of S. Maria delle Vigne (M. D'Andrea-E. Serpe)

Inside the bell tower the situation is much more complicated. Here there are several different structures - many of which were plastered over - which prevent an easy interpretation of the stratigraphic relationships. Therefore, in this case, a detailed survey of the surfaces was essential in highlighting any anomaly

2 Following the realisation of the survey and of the 3D model, we calculated that walls of the bell chamber develop for $157 \mathrm{~cm}$ and the mullioned windows for $80 \mathrm{~cm}$. The stone spire weighs around 286 tonnes and the bells around 6 tonnes.

3 The church is mentioned in documents dating 1803 as built over a previous church from 980-991. This had also been built on the ruins of chapel destroyed by a Saracen raid in 936-937 (Ceschi, 1981).

4 According to historical sources, the cloister was built in 1100 when the collegiate church of S. Maria delle Vigne was built (Ravara, 1925) 
so to focus the investigation on specific parts of the artefact. For example, it was possible to distinguish the stairs leaning onto flying short-span vaults (where the curve is so minimal that it could be misunderstood for a plastering junction) from the stairs leaning onto flying buttresses. The small recurring formal anomaly allowed us to focus on the difference, trying to find a way to evaluate the bearing structure, which had been covered with plaster and therefore was not visible. Through a thermographic survey, it was possible to visualise the disposition of the bricks and distinguish the two different types of stairs, which were built in different periods. Surveying also proved essential in the comparative evaluation of the thickness of vaults, floors, and stairs. In fact, some structures are visible and can be surveyed with a high level of technological detail, while other structures that were plastered or covered by a false ceiling are not visible and therefore, can only be compared from a formal point of view. In this case, information on curving, shape and thickness of a given element was essential to group the various types of vaults, floors, and stairs. Thanks to this interpretative projection, it was easier to verify a hypothesis in specific significant parts of the constructive elements, which undoubtedly facilitated a better understanding of the bell tower.

\subsection{Three-dimensional survey}

The bell tower of the Basilica delle Vigne was analysed with an accurate three-dimensional survey carried out with the $\mathrm{Z}+\mathrm{F}$ Imager 5006h laser-scanner device together with the topographic support of the Leica TS15-A station. Due to the architectural and formal complexity of the bell tower, it was necessary to instal a large number of laser stations and, ultimately, scans, which were united to create a rich database. This useful information which would be difficult to acquire with the usual surveying methods. The laser scans - both inside and outside the tower - were executed by 44 stations, with the definition of mainly one point every $7 \mathrm{~mm}$ at a distance of 10 metres. The outside scans to obtain the layout of the bell tower, were taken from the balconies of the surrounding buildings around 30 metres away from the tower - with a higher acquisition setting in order to guarantee a dense point grid for the restitution phase. The resulting dense point cloud generated a three-dimensional representation of the studied object with a level of accuracy below 1 centimetre ${ }^{5}$, thanks to which the areas in partial view could also be obtained. This helped the process of data registration and restitution, and it created an exhaustive database which was essential for a reliable restitution of a model constituted by ideal surfaces, which were necessary during the stage of structural analysis ${ }^{6}$.

The scans were taken both inside and outside the bell tower with the aim of acquiring as much information as possible, despite the many difficulties caused by the constrained work area, located within the dense old city centre of Genoa (Figure 3 ). This meant, for example, that it was not possible to survey the south side of the bell tower, which faces the cupola, because

The use of phase variation lasers, because of the technology implemented, guaranteed a level of accuracy below 2-3 mm. However, the laser also has a limited range which in the case of the equipment used is 79 metres (Guidi et al., 2012).

6 The acquisition of geometrical data allows a better understanding of the structure and a digital architectural reconstruction, which is adherent to reality for static analysis (Caroti et al., 2003).

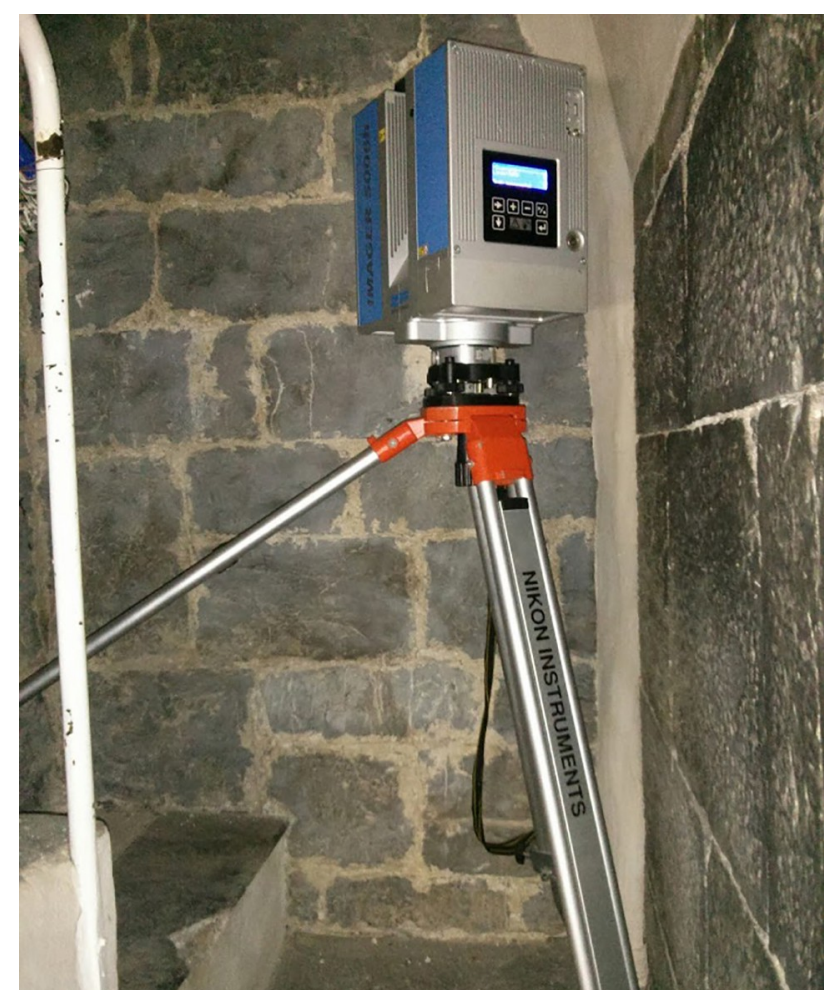

Figure 3. Image of laser scanner station inside the bell tower there were no potential locations fitting the range of our equipment.

Parallel to the laser scanning process, a topographic survey campaign was carried out to have better control when connecting the single laser scans. The sparse point cloud, generated by the topographic equipment, acquired both geometrical points, specific to the building, and targets, preliminarily located on the surfaces, so that they could be acquired both during the topographic survey campaigns and the laser survey campaigns. The targets, which are automatically recognised by the Laser Scan software managing the point clouds, were organised by the Leica Cyclone 9.0 software, which can regulate the level of precision that each target should have when calculating the roto-translation of the laser point clouds on the reference system defined by the topographic survey.

The elaboration of the point cloud allowed the creation of both the classic two-dimensional representations (plans, layouts, and sections) as well as a simplified model for the analysis of the finished elements. Many scientific contributions explain how using three-dimensional surveying techniques is fundamental to the analysis and the structural investigation of buildings (Caroti et al., 2012; Caroti \& Fangi, 2004; Visintini \& Spangher, 2013).

In order to generate two-dimensional compositions, the threedimensional point cloud was converted and imported into the software ReCap 360 Pro, produced by Autodesk. This application is easy to use and it offers the possibility of an interactive viewing together with the creation of separated layers useful to manage a complex piece of architecture such as the studied tower. Another important feature of the software for the drafting phase of compositions, is the possibility to import the point cloud into the AutoCad software and to section the point cloud to obtain the essential geometry of the bell tower. 


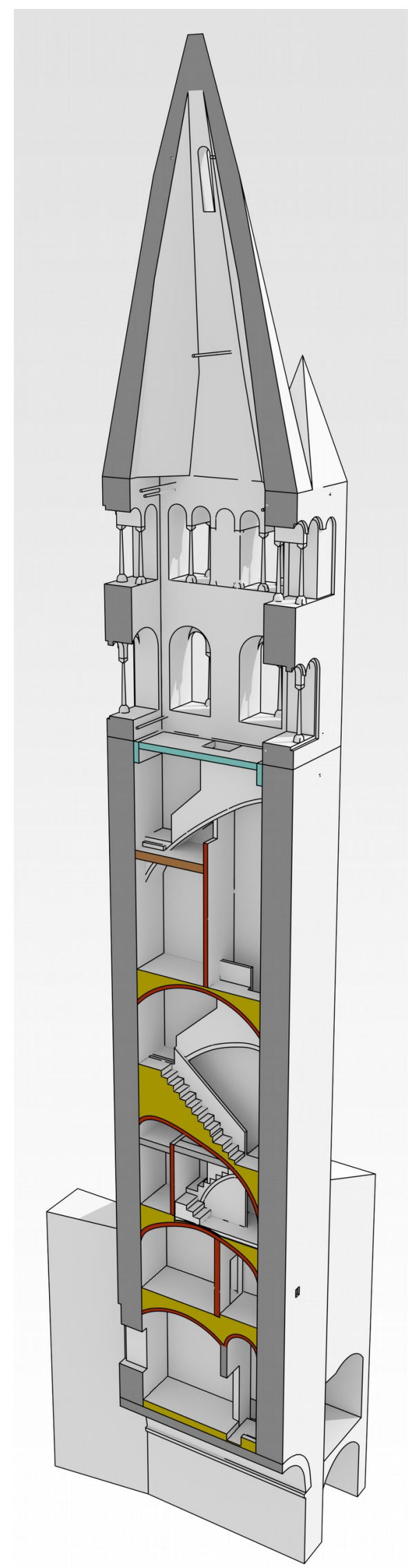

Figure 4. Retopology of the bell tower and schematization of the materials used: grey=stone; red=brick; yellow=filling; brown=wood; cyan=concrete (B. Di Napoli)

\subsection{Bell tower retopology}

Retopology was implemented to transform the database from the point cloud to a three- dimensional model for structural surveys. Retopology is the conversion of the quantitative and qualitative information of the point cloud into models made up of simplified surfaces. These models can be represented by parametric surfaces or by a set of vertexes, borders or faces, known as a mesh. The conversion of numerical information inevitably leads to variations from the real model of the structure, which, if controlled during the construction phase, do not cause substantial variations in the structure evaluation.

The simplified three-dimensional models can be generated with a series of retopology techniques. In the most common technique, high-definition orthographic images are redrawn in CAD. With the extrusion control, the operator can build a representative model of the studied building. However, this method can create an approximative model and can have significant limitations. This is because historical architectural buildings can almost never be represented by perfect flat or curve surfaces, and this can lead to fundamental mistakes in the structural calculations.

Another common method in building models requires the use of specific software able to generate complex surfaces starting from the point cloud. However, due to their size and high definition, these three-dimensional models cannot be used within the software for the calculation of finished elements. The operator is then forced to simplify the model by using reduction filters for the vertexes and to correct any mistakes regarding the creation of the triangular mesh - this inevitably elongates the retopology process.

The method used in the present case required the creation of a three-dimensional model in NURBS ${ }^{7}$ surfaces with vertical and horizontal sections as reference. The result is a threedimensional model, which, thanks to the characteristics offered by NURBS modelling, is constituted by a lower number of surfaces, providing at the same time a reliable representation of the architectural complexity of the building (Figure 4). The conversion from NURBS surfaces to mesh is then resent to the software for structural calculation, which, with its parameters, creates the optimal polygonal framework for the structural calculation. In the present case, we decided to use Rhinoceros, the software produced by McNell. During the modelling stages of the bell tower, a significant number of layers were created, which are essential to simplify and manage the information gathered in the survey campaign. With the addition of internal walls, external walls and the division in vertical sectors, it was possible to analyse the bell tower through its materials, which are fundamental in the subsequent structural simulations. The elaboration phase of the model helped in understanding the architectural complexity of the bell tower and it allowed us to examine in detail some aspects of its historical evolution.

\section{THE ABBAZIA DI SAN MATTEO IN GENOA}

The Abbazia di S. Matteo is located close to the Basilica delle Vigne and it is a church built in the thirteenth century by the powerful Doria family nobility. At the time, Genoa was divided into unions of noble families and the Doria family was among the most powerful. The Abbey was built in 1278 upon the remains of a previous church that had been commissioned by a member of the Doria family, but which no longer reflected the

The Non-Uniform Rational Basis-Spline (NURBS) are a mathematical model used to define curves, surfaces, and solids. 
growing power of the family. In the first half of the sixteenth century, A. Doria appointed G.A. Montorsoli to renew the crypt, the chancel, and the cupola, although, the largest part of the work was executed in the second half of the sixteenth century. G.B. Castello, known as Bergamasco, and L. Cambiaso were then appointed to radically renew the design of the Abbey. They decided to significantly widen its volume by modifying the proportion of the hall, decorating it with mural paintings and stuccos (Figure 5). In 1934, the Abbey was restored by O. Grosso, who mostly worked on its façade with its black and white striped design.

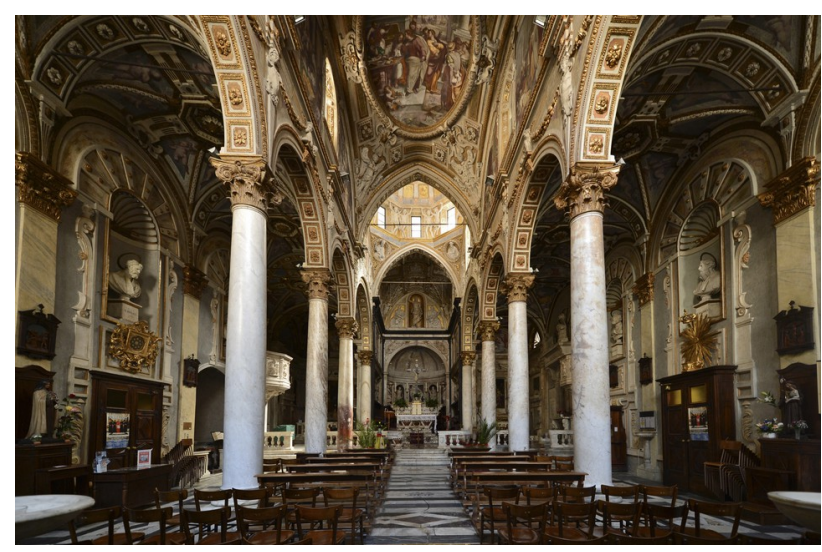

Figure 5. The church during the Reinassance (R. Lavezzaro)

\subsection{The diagnosis and monitoring project}

The Abbey has had serious problems with rising damp both in the hall, where the damage is particularly evident on the walls of the lateral aisles, and in the space below the crypt, which was rediscovered in 1962 during a restoration campaign. Humidity in churches is an old problem, as shown by a series of interventions by Montorsoli in the sixteenth century to improve the crypt's aeration (i.e. the air duct reaching the roof and grates connecting the crypt and the hall). Even recently, in 1992, the Superintendence of Cultural Heritage led an intervention of dehumidification by injecting a chemical barrier along the longitudinal walls of the hall. Despite this, the Abbey, built on clay-marlstone soil at the edge of a natural slope, which is now urbanised, is located in an area favouring the collection of rainwater that filters down from the soil and gathers in an underground aquifer. In the adjacent cloister, there is a well intercepting water at 1.5 metres from ground level, i.e. in correspondence with the abbey's foundations (Figure 6).

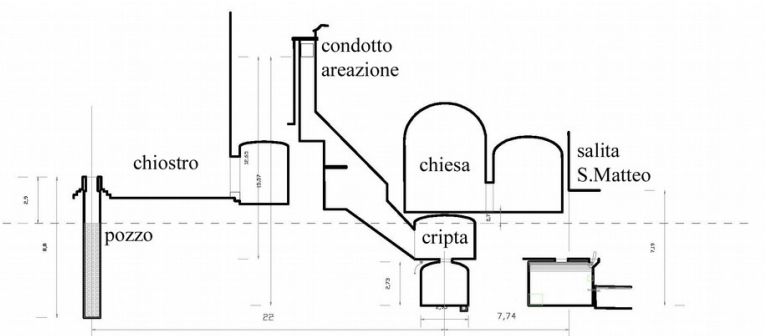

Figure 6. Schematic section of the church with crypt, underneath area, lateral cloister, and well (R. Lavezzaro)
Moreover, the space below the crypt, which in 1962 was found full of water, was believed to be a sewage pipe to collect rainwater. This was also due to the presence of a water duct, which was closed during the intervention to avoid constant flooding. During the flooding in October 2014, this area flooded again and even two months after the event, there was still $60 \mathrm{~cm}$ of water.

The conservation of stuccos, marble, mural paintings and artwork in the Abbey is currently threatened by humidity as well as the formation of saline efflorescence, which lead to widespread phenomena of disintegration, pulverisation and exfoliation. For this reason, in 2012, the Abbot decided to try using an active system of wall dehumidification, which works with electromagnetic waves. Subsequently, in accordance with the Superintendence, the decision was made to monitor ${ }^{8}$ the humidity levels in the hall of the Abbey and in the space below the crypt. The monitoring process ended in 2016. After the first values of humidity were taken in December 2012, before the installation of the devices, the survey was carried out over three years, around every 6 months. There were essentially 4 types humidity measurements: environmental, superficial (resistive $\operatorname{method}^{9}$ ), sub-superficial at $4 \mathrm{~cm}$ from the surface (capacitive $\operatorname{method}^{10}$ ), and deep measurements at 9 and $14 \mathrm{~cm}$ from the surface (weight method ${ }^{11}$ ).

\subsection{Surveying as an aid to monitoring}

During the monitoring process six survey campaigns were carried out, which, each time, investigated the same points and parameters to obtain values compatible between each other, in order to evaluate the actual effectiveness of the installed devices. The environmental data and the data connected to the humidity levels measured deep within the walls were organised in charts, and visualised in diagrams. The survey points were chosen based on their relevance, but also on the effective possibility to drill a hole in the walls to take a sample of the humid material. On the other hand, regarding the values of superficial and sub-superficial humidity, which are not invasive, a higher number of data was gathered to effectively represent the variation in humidity on the surfaces. The values were recorded based on a 30x30 grid along all the walls of the hall and the space below the crypt, starting from the ground and arriving at 2 metres. The crypt was excluded from the measurement process, apart from the environmental monitoring, because it is completely decorated with marble and stuccos.

The superficial measurements could have also been gathered and then transferred onto charts, but because of the great quantity of data collected, it would have been extremely difficult to compare it and obtain a complete picture of the situation. Hence, the need for a tool, that was easy to use and

\footnotetext{
The monitoring process was carried out within the convention with the Architecture and Design Department (scientific coordinator, prof. S.F. Musso and arch. R. Vecchiattini), the Parish of S. Matteo (Mons. G.C. Rapallo), the Curia of Genoa (dott.ssa G. Di Natale) and Ecodry Italia srl (R. De Rosa) together with the dissertation team of Construction Engineering-Architecture, Genoa ( $R$. Lavezzaro).

9 Non-destructive method that measures the electrical resistance of a material which diminishes in relation to the quantity of water contained in it (Protimeter Mini e Protimeter Surveymaster).

10 Non-destructive method that measures the dielectric constant of a given material which sensibly increases even with small quantities of water (GANN BL compact B e Protimeter Surveymaster).

11 Destructive method that measures the quantiy of wanter in a material sample, which is weighed immediately after having been taken and after having dried with a thermoscale (Kern DLB).
} 
was able to gather and visualise a great deal of information on site. Consequently, the tree-dimensional survey and the algorithm created expressly for the present case, accelerated the work process and showed the phenomena observed in a clear form.

\subsection{Three-dimensional survey}

Digital surveying spatially organises the areas in their integrity, while diagnostic surveying provides useful information on each single case. In the case of the Chiesa di S. Matteo the correlation between the information on the thermo-hygrometric conditions of the artefact and the space of the architectural elements was essential for effective monitoring.

The presence of crypts on two levels, which one can access through an internal ladder and a trapdoor, and the presence of an ancient duct for natural aeriation - which has never been inspected - together with the lack of specific information, created a necessity for more detailed knowledge about the position of both crypts and the air duct, in order to understand their relationship with the church and the surrounding environment.

Understanding a historical piece of architecture is a difficult process leaving the researcher with many uncertainties, which means that every piece of information obtained becomes fundamental, as it enriches the collective knowledge on built architecture throughout the centuries. For this reason, the decision was made to acquire the metrical information on the entire church to better understand the building and correctly localise the hygrometric data within a three-dimensional space. Laser-scanner and topographic acquisition systems were simultaneously used during the three-dimensional survey campaign. The topographic acquisition systems were extremely relevant in connecting the two crypts. In fact, the passageway through a trapdoor between the two spaces, made it particularly difficult to use the registration systems, which exploit natural geometrical points. With the Z+F Imager 5006h, phasevariation scanner with panoramic imaging, 28 stations were used for a three-dimensional survey of the two crypts, the church interior, the main façade, and the square in front of the church, Piazza di S. Matteo (Figure 7).

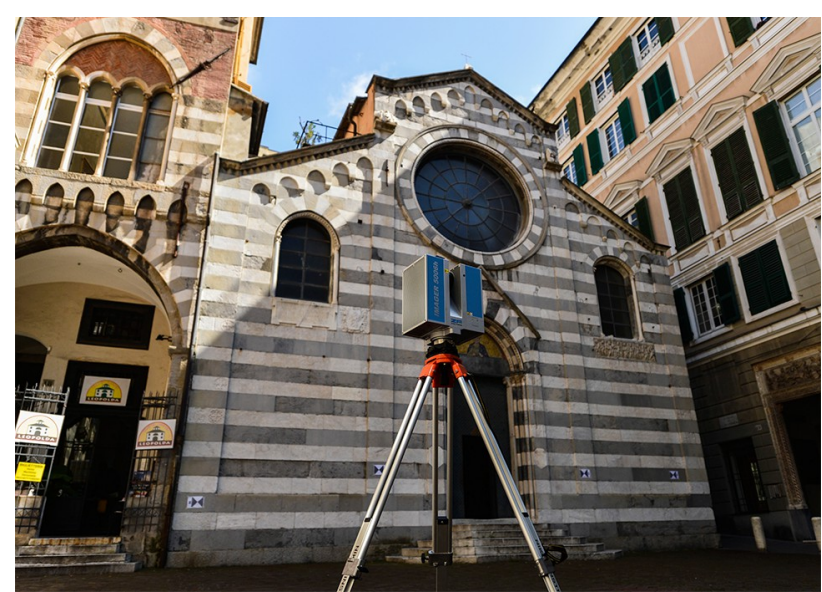

Figure 7. Scan position to acquire the point cloud of the Chiesa of S. Matteo facade (R. Lavezzaro)

These shots were subsequently roto-translated onto the main reference system identified with the topographic survey, executed with Leica TS15-A, a total motorised station with a laser plummet and circular level. Through the definition of an open polygon with five vertexes, it was possible to obtain the flat targets, essential for the registration stage of the laser point clouds (Leica Cyclone 9.0 software). The data gathered was then elaborated to obtain a database from which it was possible to take high-definition images of the church $(15000 \times 7361$ pixels), with metrical information, able to describe the architectural complexity of the building.

During this phase, all the objects that were not part of the architectural representation were deleted from the point cloud, such as furniture or people that were in range of the equipment used. Thanks to the characteristics of the management software, it was possible to create shaded visualisations, with false colours and in greyscale, which made the architecture and decoration of the space visible. These images were then used as a reference for the following elaborations.

\subsection{Data paramentric representation}

To visualise the great amount of the gathered hygrometric data, an interactive system was created using the software for threedimensional modelling, Rhinoceros3D and Grasshopper ${ }^{12}$, the plug-in for visual programming. Tests show how Grasshopper is a valid tool to analyse the database for complex illuminotechnical simulations (Park, 2013) or to extract threedimensional information from complex models (Calderini, 2016) (Figure 8).

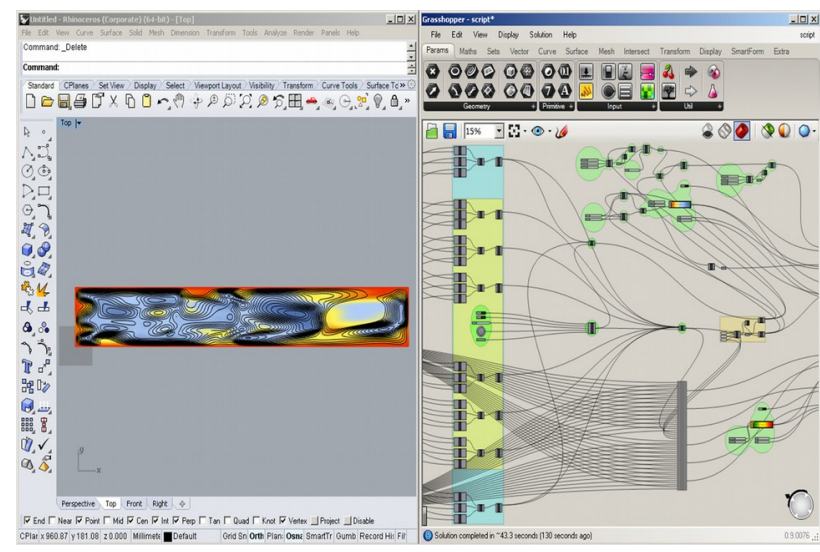

Figure 8. Processing of data within the plugin Grasshopper inside Rhinoceros (R. Lavezzaro)

In the first stage of the project, the gathered diagnostic data was recorded into an Excel table - adding for each piece of data the $\mathrm{XY}$ coordinates of the sampling point in the planar photo of the investigated wall. Using specific nodes and scripts in Grasshopper, it was possible to manage the workflow for the generation of three-dimensional models in NURBS surfaces representing the section of the analysed wall. In particular, a first input node was created to which the user can associate the chart with the diagnostic measurements, thus allowing the application to separate the data of the single survey campaigns in different subfolders. The subsequent stages of the designed script were: three-dimensional modelling, analysis of the single

\footnotetext{
12 Grasshopper is free visual editor for scripting which does not require programming notions. Through an intuitive graphic method based on node interface, the user can define sequences of instructions that will be translated into three-dimensional models in the Rhinoceros window. The modelling process is implemented with algorithms and operations allowing the calculation of a desired result starting from input data with a logic and finite sequence of elementary instructions.
} 


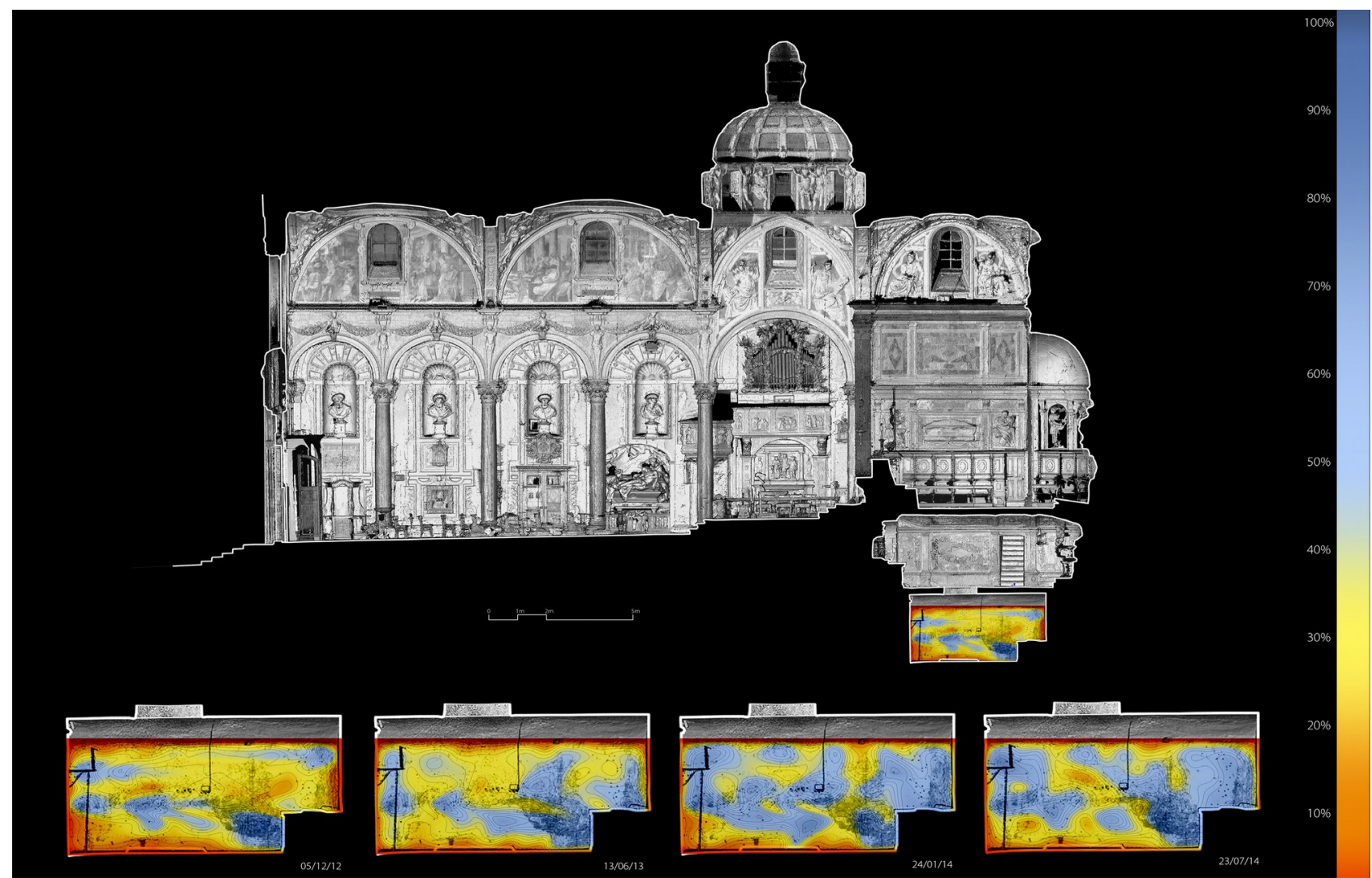

Figure 9. Rappresentation the humidity levels measured and survey data of the lower crypt (R. Lavezzaro)

generated surfaces, differential analysis between different surfaces, and restitution through a reference graphic layout. When creating the NURBS surfaces, the hygrometric data, represented by the $\mathrm{XY}$ coordinates and by the measurement value associated to the $\mathrm{Z}$ value, were converted into interpolated curves that, through the loft control, generated the NURBS surface of the investigated wall. Thanks to the interpolation properties of the loft control it was possible to simulate the hygrometric conditions that had not been detected among the different measurement points. During the subsequent phase, the 3D surface was compared (using the distance factor) with the reference plane built by the edge curves, thus generating a representation in false colours of the three-dimensional trend of the surface.

This visualisation graphically represented the condition of the walls, providing an accessible overview of the numerical values of the measurements. Subsequently, the algorithm compared the surface, that was just built, with the previous temporal state and using the distance factor, it generated a differential comparison of the surfaces. This method graphically highlights the variations in the measurements acquired in different times, creating a parametric relationship between the measured data and the geometry of the wall (Figure 9). In order to quantitatively analyse these graphic renderings, the decision was made to implement a system to create a visualisation in contour lines of the processed data with scanning interval that can be defined by the user.

Lastly, the compositions, produced by the script, are automatically inserted in a predetermined print layout with the indication of the analysed area and a reference legend.

\section{CONCLUSIONS}

The two case studies show how different goals can lead to the necessity of different techniques and survey equipment or to an unsual use of the same tools.

The technology of digital surveying generates databases containing spatial coordinates that are indispensable for the definition of the architecture. Three-dimensional point clouds represent - nowadays with a very high level of precision - the architectural complexity of the objects studied. However, in ield of data management and representation, digital tools are used not just for the creation of databases and three-dimensional models, but also to spread information. Software and tools are used to manage the large amount of information gathered in the separate survey campaigns by experts in different disciplines. Digital representation becomes the tool thanks to which a greater number of experts can cross-check and interpret data from perspectives that might differ greatly from one another.

In the field of restoration, it is not difficult to meet the needs of specialization: there are many different skills required and there are many professional roles involved with essential multidisciplinary knowledge. If we consider restoration as intervention on historical buildings, then researching it becomes even more complex because of the many disciplines involved, i.e. history (in its broader sense), hard science (with relation to analytical aspects), or social sciences (for the reinsertion of the artefact in the economic flow). In restoration, we often require the aid of various experts to deal with multiple aspects within a continuous process of analysis and synthesis, which forces all parties involved to adopt a broader point of view even if we are all studying one single object.

Digital techniques become useful tools in the analysis and synthesis of the issues arising in the process of researching. 
They prove to be ever more useful the more researchers share information on the project and its goals.

In the case of the bell tower of the Basilica delle Vigne, the ideas coming from the discipline of architecture archaeology with the aim (specific to structural engineering) of using modelling to predict the possible behaviour of the studied structure, found a point of convergence in digital surveying. Likewise, in the case of the Chiesa di S. Matteo, the physicaltechnical evidence together with the requirements of diagnostics led to the creation of fundamental systems to visualise and manage information. The common ground among all these discipline is restoration as well as the common goal to preserve the material integrity of a studied artefact and to protect and pass on its cultural values.

The developments in applied science are significant when compared to research in restoration ad surveying twenty or thirty years ago. However, the same cannot be said for the theory of these disciplines. Many view cooperation among different fields of knowledge as a risk of contamination which will translate into a loss of identity or autonomy.

But science survives only if it has the courage to renew itself. ${ }^{13}$

\section{ACKNOWLEDGEMENTS}

The authors would like to thanks Mons. N. Anselmi e Mons. G.C. Rapallo, and A. Schiappapietra, M. D'Andrea, E. Serpe, B. Di Napoli, R. Lavezzaro e R. Babbetto for their work on site.

\section{REFERENCES}

Caroti, G., De Falco, A., 2003. Geometric survey for the structural assessment of the architectural heritage: the case of the Baptistery of S. Giovanni e Reparata in Lucca. in International Archives of the Photogrammetry, Remote Sensing and Spatial Information Sciences - ISPRS Archives, Vol. XXXIV, pp. 111-116.

Caroti, G., Fangi, G., 2004. Il rilievo della volta interna del Battistero in S. Maria del Fiore e le chiese fiorentine del duecento e del trecento nella città delle fabbriche arnolfiane. Alinea, Firenze, pp. 145-148.

Caroti, G., Franconi, A., Piemonte, A., 2012. Metodologia di elaborazione dati laser scanner per la generazione di modelli utili al calcolo strutturale, Proceedings of $16 \mathrm{a}$ Conferenza Nazionale ASITA, pp.383-390.

Ceschi, C., 1981. Chiese di Genova. Stringa, Genova.

Guidi, G., Remondino, F., 2012. 3D Modelling from Real Data, in Modeling and Simulation in Engineering, edited by $\mathrm{C}$. Alexandru, InTech, pp. 69-102.

Ravara, G., 1925. Sancta Maria in Vineis. Marsano, Genova.

Vecchiattini, R., D'Andrea M., Schiappapietra A., Serpe E., 2016. Conoscenza e visitabilità: il progetto di restauro del campanile di Santa Maria delle Vigne a Genova, Atti del $4^{\text {th }}$ International Conference on documentation, conservation and restoration of the architectural heritage and landscape protection ReUSO edited by S. Parrinello and D. Besana, Edifir, Firenze, Vol. III, pp. 988-996.

13 Paragraphs 2.3, 2.4, 3.3 and 3.4 were written by C. Battini, while R. Vecchiattini wrote the remaining paragraphs.
Visintini, D., Spangher, A., 2013. Rilevamento laser scanning, modello della superficie (DSM) e modello per il metodo agli elementi finiti (FEM) di una struttura, Atti della $17^{\text {a }}$ Conferenza Nazionale ASITA, pp. 1287-1294. 